\title{
Representaciones sociales de arte urbano en Barranquilla (Killart, 2017)*
}

\section{Social representations of urban art in Barranquilla (Killart, 2017)}

\begin{abstract}
Aura Aguilar-Caro, Ph.D.
Universidad Simón Bolívar, Barranquilla, Colombia. Grupo de investigación: Estudios Interdisciplinarios del Caribe. Doctorado en Educación Intercultural, Trabajadora Social. Docente-Investigadora. Correspondencia: aaguilar2@unisimonbolivar.edu.co.
\end{abstract}

Recibido: 30-04-2017; Aceptado: 14-06-2017

\section{RESUMEN}

En adelante, se sintetizan las principales conclusiones del desarrollo de un proyecto de investigación que se origina desde el aula, en la asignatura Metodología de la Investigación Científica a estudiantes de Psicología en la Universidad Simón Bolívar en la ciudad de Barranquilla-Colombia. Se parte de la psicología social, a través de las representaciones sociales, para realizar el trabajo de campo, cuyo objeto de investigación es un proyecto de arte urbano (imágenes en paredes) en BarranquillaColombia, mediante observaciones directas, revisiones documentales y entrevistas. Se analizan las imágenes que emergen en cada uno de los murales del proyecto de Arte Urbano Killart 2017; y se define la categoría de las representaciones femeninas, masculinas y naturaleza. En ese contraste, el objetivo central fue que los/las estudiantes se acercaran a la realidad y ocupando técnicas de investigación, pudieran interpretarla, considerando que Barranquilla es una de las ciudades que tiene el desafío de comprensión de lo femenino, que en el caso de la violencia hacia la mujer, viene ocupando los primeros lugares del país en cuanto a feminicidios se refiere. Se ha derivado de este trabajo en conjunto con la participación de los/las estudiantes un documental, en el que se pone de relieve el tema de lo femenino y la importancia de la mujer, se resalta su valor humano y el capital cultural que la define en el aporte de la construcciones familiares y sociales en nuestro entorno caribe.

Palabras clave: Arte urbano, representaciones sociales, metodología de la investigación. 
Aguilar-Caro - Representaciones sociales de arte urbano en Barranquilla

\section{ABSTRACT}

From now on are summarized the main findings of the development of a research originates at the classroom, in the Scientific Research Methodology class to psychology students in Universidad Simón Bolivar in Barranquilla-Colombia. It starts from social psychology, through social representations, to do fieldwork; whose subject of investigation is an urban art project (images on walls) in Barranquilla Colombia, across direct observation, desk reviews and interviews. Images that emerge in each one of wall-mounted of Art Urbano Killart 2017 are analyzed, defining female, male and nature representation category. In that contrast the main goal was that students get close to reality and through research techniques could interpret it, considering that Barranquilla is a one of the city which has the challenge of female, understanding that in the violence against woman case, has the first places of the country in what Femicides refers. From this work has been derived with student's collaboration a documentary by stressing female topic and importance of women, highlighting her human value and the cultural capital which define her in the contribution of family and socials constructions in our Caribbean environment.

Key words: Art urbano, social representations, scientific research methodology.

\section{INTRODUCCIÓN}

\section{Arte Urbano Killart 2017}

En la actualidad el desafío de conocer desde la investigación, acerca de la transferencia de conocimiento referido al aula; da apertura a nuevas formas de hacerlo. Se considera que los/ as estudiantes pertenecen a una generación de nativos/as digitales, llamar su atención en torno a temas de investigación que conciernen a dos actos fundamentales: leer, escribir y la combinación de los dos: producciones textuales que definidos por estrategias metodológicas y sumados a la apropiación de un discurso académico, con un lenguaje técnico, no hace atractivo que los/las estudiantes puedan centrar la atención en tema de investigación, que como proceso, es un trabajo que requiere además, incorporar lógica, disciplina y perseverancia, hasta lograr el cometido. Basado en una proyección desde las identidades culturales, y la historicidad acumulada como sujetos/as de la historia en el contexto latinoamericano (Zemelman, 1992).
En ese sentido, dentro de la asignatura Metodología de la Investigación Científica con estudiantes de tercer semestre de Psicología, en la Universidad Simón Bolívar de Barranquilla- Colombia, se propone hacer práctico lo que se define en el aula como metodología de la investigaciones científica de corte cualitativo; de esa manera se planifica un proyecto extramural denominado "la dialéctica femenina de la imagen en Killart 2017", que además de hacer prácticas dos (2) técnicas de investigación como: entrevistas, y observaciones directas; se pueda palpar la realidad e interpretarla, en este caso desde las representaciones sociales, la cual es una teoría que permite develar los saberes comunes articulados con el conocimiento científico, para sustraer aquellas realidades ocultas.

En concordancia con lo anterior, se tomó como objeto de investigación al proyecto de Arte Urbano Killart 2017, cuyas imágenes representan cotidianidades universales y que a través de este trabajo investigativo se resignifica la educación para la cultura y la riqueza que guarda dentro del epicentro caribe. Llegando hasta las fuentes directas desde quienes planearon (Cultura Distrital y 
Alianza Francesa) y ejecutaron (artistas locales) el proyecto; para contrastar sus percepciones y así lograr un análisis mayormente real de las pretensiones académicas, pero que además pueda llegar a la ciudadanía como aporte a las construcciones de los imaginarios que emiten los murales y aquellas que al desdoblar la imagen se traducen en contenido social.

De otra manera, considerando que en la actualidad, según el investigador Rojas Mix (2015), quien manifiesta que América Latina ha pasado de una cultura alfabética a una visual y en ello hay que hacer nuevas comprensiones y abordajes (Mix, 2015). Por ejemplo en calle Broadway de New York, en la era digital se inmediatiza la imagen, la instantaneidad de tantas a la vez, que corresponden a sucesos globales no las inmortalizan. Lo contrario del arte urbano, la pintura fija permite por un tiempo poder observar y poder hacer análisis de segundo orden. En el caso del Festival Killart 2017, en Barranquilla - Colombia, el producto de las imágenes converge en representaciones femeninas en contraste con las masculinas y aspectos de la naturaleza. En ese sentido el arte, es una actividad espiritual y particular bajo la cual el espíritu se manifiesta.

En ese sentido, en El Festival Internacional de Grafiti y Arte Urbano de Barranquilla, Killart, en su tercera versión; participaron artistas locales, nacionales y extranjeros; intervinieron 15 paredes de ese sector entre carrera 50 entre calle 45 y Vía 40, del 6 al 11 de marzo de 2017. Killart es organizado por la Alianza Francesa de Barranquilla, con la Asociación Troi3 y la Fundación Lienzo Urbano. Además cuenta con el apoyo de la Secretaría de Cultura, Patrimonio y Turismo del Distrito.

Las paredes de Barrio Abajo, antes vírgenes del "Street art", se transformaron en un rústico lienzo urbano con la tercera edición del Festival de Grafiti y Arte Urbano de Barranquilla Killart. (El Heraldo, 2017). A continuación, en la tabla 1; se enlistan los artistas y los nombres de sus obras:

Tabla 1. Relación de artistas y nombre de murales.

\begin{tabular}{llc}
\hline \multicolumn{1}{c}{ CATEGORIA } & \multicolumn{1}{c}{ NOMBRE DE MURAL } & PSEUDÓNIMO DE ARTISTAS \\
\hline Artistas Local & Vendedora de cocadas & GRAFF24 \\
& Tres mujeres afro & LINDA \\
& Mujeres con cabezas de árboles y nubes & BARRAZA \\
& Perros y aves & OMAR ALONSO \\
& Animal multiforme & SHOT DMENTE \\
Artistas Nacional & Letras y cara de mujer & GRIS ONE \\
& Abstracto, súper colorido & GUACHE \\
Mujer amamantando & Notable Salazar Grafiti \\
Mrtistas Internacionales & RESO \\
& Circulo abstracto vía 40 y oso panda & CART1 \\
& Hombre caimán & HOPARE \\
& Hombre acostado fondo amarillo & VINNIE \\
& Cara de mujer con ojos grandes & KIDKREOL Y BOOGIE \\
\hline
\end{tabular}

Fuente: Coordinación de Alianza Francesa 2017. 
En suma, en un museo a cielo abierto, que convierten los quince (15) artistas que colorearon durante una semana quince (15) paredes de Barrio Abajo, que suman alrededor de 2.000 metros cuadrados. Los artistas participantes, siete (7) son franceses (Cart1, Hopare, Reso, Vinie, Goin, Kic Creol y Boggie); seis (6) barranquilleros (Graff24, Roberto Barraza, Joy, Omar Alonso, Linda Montoya y Shot); y tres (3) bogotanos (Guache, Gris y Notable). (El heraldo, 2017).

\section{Representaciones sociales e imagen como punto de partida}

El término "Representaciones Sociales" (RS) se incorporó desde 1961 por Serge Moscovici, desde entonces se ha pasado de la elaboración de un concepto a un desarrollo de la teoría que ha permeado las ciencias sociales porque constituye un nuevo enfoque que unifica e integra lo individual y colectivo, lo simbólico y lo social; el pensamiento y la acción (Araya, 2002).

En esta teoría se destaca, cómo una manera de interpretar y de pensar la realidad cotidiana, una forma de conocimiento social, está determinado por el contexto concreto en que se sitúan los individuos y los grupos, la comunicación establecida entre ellos, a través de los marcos de aprehensión que proporciona su bagaje cultural, sus códigos, valores e ideologías relacionados con las posiciones y pertenencias sociales especificas (Moscovici, 1984).

En este sentido, la imagen, es el concepto que más se utiliza como sinónimo de $\mathrm{R} S$. Tanto la imagen como la representación social hacen referencia a ciertos contenidos mentales fenomenológicos que se asocian con determinados objetos, supuestamente reales. La imagen, sin embargo, es una reproducción pasiva de un exterior en un interior. Esto equivale a decir que la imagen se construye esencialmente como reproducción mental de un objeto exterior y se relaciona básicamente con los mecanismos perceptivos (Araya, 2002).

Reproducir y producir pertenecen a distintos ámbitos y denotan la distancia entre ambos conceptos. Si bien, al igual que ocurre con el concepto de actitud, la RS integra el concepto de imagen en su propia formulación; es necesario insistir que cuando se habla de RS se parte de que no hay un corte entre el universo exterior y el universo de las personas o de los grupos y de que, en el fondo, el sujeto y el objeto no son heterogéneos en su campo común. El objeto está inscrito en un contexto activo, móvil, puesto que, en parte, fue concebido por la persona o la colectividad como prolongación de su comportamiento y solo existe para ellas en función de los medios y los métodos que permiten conocerlo (Araya, 2002).

Así pues, la noción de las representaciones sociales, nos sitúa en el punto que se intercepta lo psicológico y social, es la manera que los sujetos sociales, aprenden de los acontecimientos de la vida diaria, las características del medio ambiente, las informaciones que en él circulan, las personas del entorno próximo 0 lejano; este es el llamado conocimiento espontáneo que habitualmente se denomina conocimiento del sentido común, por oposición al pensamiento científico (Jodelet, 1984).

Haciendo alusión al análisis de las imágenes de Killart 2017; lo representacional que se deriva de esa abstracción, no son un mero reflejo del exterior, sino, que más bien, una construcción que da sentido y significado al objeto o referente que es representado (Martinic, 2006). De esa manera nos muestra el horizonte de lo femenino, en relación con lo masculino y la naturaleza. 
Finalmente, este conocimiento se constituye a partir de las experiencias, pero también de las informaciones, conocimientos que se reciben y se trasmiten a través de la tradición, educación y comunicación social; de esta manera en muchos aspectos, es un conocimiento socialmente elaborado y compartido. De esta manera, el contraste realizado entre gestores culturales, artistas; con el vínculo académico permitió elevar nuevas dimensiones en la comprensión del arte urbano.

\section{METODOLOGÍA}

Dentro de la orientación metodológica se ocupó la metodología cualitativa, que permite abstraer subjetividades a partir de la realidad y que combinadas con técnicas de investigación como la entrevista y la observación directa, en este caso facilitan la comprensión de lo propuesto en el análisis de la dialéctica de la imagen femenina, en el proyecto Killart 2017. En la tabla 2, se describen las técnicas empleadas.

Tabla 2. Técnicas de investigación y actores participantes.

\begin{tabular}{|c|c|c|c|}
\hline $\mathbf{N}$ & $\begin{array}{c}\text { Técnica de } \\
\text { investigación }\end{array}$ & $\begin{array}{l}\text { Sujeto/ } \\
\text { Objeto }\end{array}$ & Actores participantes \\
\hline \multirow{5}{*}{1} & \multirow{5}{*}{ Entrevistas } & \multirow{5}{*}{5 Personas } & Secretario de Cultura Distrital \\
\hline & & & Académico \\
\hline & & & $\begin{array}{c}\text { Coord. Cultural Alianza } \\
\text { Francesa }\end{array}$ \\
\hline & & & Artista 1 \\
\hline & & & Artista 2 \\
\hline 2 & $\begin{array}{l}\text { Observación } \\
\text { Directa }\end{array}$ & 14 Grafitis & $\begin{array}{l}30 \text { estudiantes de tercer } \\
\text { semestre de Psicología a }\end{array}$ \\
\hline & TOTAL & $\begin{array}{l}5 \text { Personas } \\
14 \text { Grafitis }\end{array}$ & 35 Actores participantes \\
\hline
\end{tabular}

Fuente: Elaboración propia a partir de las técnicas aplicadas.

A partir de la fuente se obtuvo el trabajo de campo, del trabajo de campo; se procede a analizar, desde la técnica de investigación análisis de contenido; se define como la clasificación de las diferentes partes de un escrito conforme a categorías determinadas por el investigador para extraer de ellas una información predominante o las tendencias manifiestas. Esta técnica, ha sido utilizada en el análisis de producciones orales radiales, programas de T.V., imágenes, propagandas políticas, libros infantiles, etc. (Pardinas, 1993).

Los instrumentos elaborados para las entrevistas y observaciones directas, se definieron mediante dimensiones, que permiten realizar los respectivos análisis. En las tablas 3 y 4 , se detalla esta información anteriormente descrita:

Tabla 3. Instrumentos para realizar las entrevistas a actores participantes.

\begin{tabular}{|c|c|c|}
\hline $\mathbf{N}$ & Dimensiones & Aplicado A: \\
\hline 1 & ARTISTICO & Artistas participantes \\
\hline 2 & CULTURAL & $\begin{array}{l}\text { Secretario de cultura distrital, Coordinador Cul- } \\
\text { tural Alianza Francesa, Artistas, Académico. }\end{array}$ \\
\hline 3 & SOCIAL & $\begin{array}{c}\text { Artistas participantes Secretario de cultura } \\
\text { distrital, Coordinador Cultural Alianza Francesa, } \\
\text { Artistas, Académico. }\end{array}$ \\
\hline 4 & ACADEMICO & $\begin{array}{c}\text { Artistas participantes Secretario de cultura } \\
\text { distrital, Coordinador Cultural Alianza Francesa, } \\
\text { Artistas, Académico. }\end{array}$ \\
\hline
\end{tabular}

Fuente: Elaboración propia a partir de instrumentos laborados.

Tabla 4. Instrumento para realización de observaciones directas en los murales

\begin{tabular}{|c|c|c|}
\hline Grupo & Dimensión & Interrogantes \\
\hline 1 & $\begin{array}{c}\text { Características } \\
\text { generales }\end{array}$ & $\begin{array}{l}\text { ¿Cuantos murales hay? Contar desde la plaza } \\
\text { de la aduana de lado y lado. Numerar los } \\
\text { grafitis y al lado colocarle el contenido. Tomar } \\
\text { foto a cada uno al relacionarlos. } \\
\text { ¿Dimensiones aproximadas de cada uno? }\end{array}$ \\
\hline 2 & $\begin{array}{l}\text { Contenido } \\
\text { Social }\end{array}$ & $\begin{array}{c}\text { Relacionar los grafitis y detallar su contenido } \\
\text { social. Por ejemplo si es una mujer afro, que } \\
\text { significado tendría. }\end{array}$ \\
\hline 3 & Cultural & $\begin{array}{c}\text { ¿Qué impacto causaría cada uno de estos } \\
\text { murales en los transeúntes? }\end{array}$ \\
\hline 4 & Artístico & $\begin{array}{l}\text { Desde el arte que significado tendría, vincular } \\
\text { contenidos socialmente excluidos. }\end{array}$ \\
\hline
\end{tabular}

Fuente: Elaboración propia a partir de instrumentos laborados.

Para concluir este segmento; del trabajo de campo realizado y con la finalidad de aplicar el rigor científico, se entregaron consentimientos informados a los actores participantes a través de las 
entrevistas, los cuales fueron explicados detalladamente y fueron firmados; para que fuera tenidos en cuenta para la publicación de los productos que se derivan de este trabajo, a través de un (1) documental y (1) artículo para revista científica.

\section{RESULTADOS}

Lo representacional en las imágenes Killart 2017, es una apuesta desde el arte, que permite desdoblar la imagen e identifica su contenido socio-cultural, lo cual permite educar en el sentido de lo representativo, definido por los artistas, los temas que ocupan y su realidad.

Los quince (15) murales que dieron vida dieciséis (16) artistas; entre ellos del nivel local (6), nacional (3) e internacional (7). Las tipificaciones de las imágenes desarrolladas por los artistas, se encuentran entre lo disímil de lo femenino y masculino; contrastado con imágenes que describen la naturaleza y animales.

Se visibiliza como currículo oculto, la mayoría de los murales son representaciones femeninas; siete (7) de los quince (15) murales. De ellos los artistas locales (4) son quienes más las replican. Siendo los nacionales (1) y los internacionales (Francia, 1). Están definidos por imágenes de mujeres que priman dentro de lo tradicional y apegado a la cultura del Caribe, enmarcada dentro de la identidad afrocaribe; se detalla lo reproductivo del género, la identidad y el trabajo (murales, 2,3,4,5, y 7). Dentro de nuevas propuestas tanto de la imagen como de lo que puede representar lo femenino, se encuentran dos murales (1 y 6), donde se abstraen definiciones más actuales de la mujer, en torno a lo estético de su físico y el simbolismo de su parte pensante (cabeza) que al ser eliminada de la imagen, dan luces desde lo medioambiental, sus cuidados e importancia. De allí el contraste entre lo tradicional y moderno, como sujeta situada (Ver tabla 5).

Es importante anotar, dentro del escenario del país, lo que viene simbolizando la violencia contra la mujer, que es concretado en los feminicidios; a nivel local (Barranquilla) hay un promedio en los últimos tres años de cuarenta (40) al año. Lo que puede servir como un vínculo dentro de la consciencia colectiva, de los/las ciudadanos/as, la importancia que cobra la mujer dentro de la sociedad más allá del mundo privado donde estuvo represada durante siglos.

Al interrogar a uno de los artistas locales, el porqué de su iniciativa de plasmar una imagen femenina, contestó: "mi intención fue más por el recuerdo de mi pareja, lo que ella es para mí y lo definí en el mural". Aunque aparentemente no hay correlación con la situación actual de la mujer, a nivel general, los artistas coincidieron en elevar esta categoría, como un punto de partida para las decodificaciones que los transeúntes deben hacer; para aquellas incorporaciones personales, que en este caso pueden surtir algunos efectos para la educación social.

Congruentemente, en las dos o tres últimas décadas, se han desarrollado nuevos sugerentes y enfoques teóricos sobre la participación de los distintos movimientos sociales, incluyendo al movimiento feminista; ya no solo es una visión desde la lucha de clases, sino, es la búsqueda de reconocimiento, a partir de las identidades diferenciadas. (Amorós y De Miguel, 2007; Femenías, 2007, Cobos, 2006). Aquí en este trabajo de Killart 2017, como currículo oculto, se encuentra el reconocimiento, sobre todo, de lo ancestral de aquellas mujeres que hicieron parte de las generaciones actuales en las distintas etnias, confabuladas, con la mujer contemporánea que busca nuevas rutas para su desarrollo y apropiaciones. 
En ese sentido, se puede articular este análisis, lo considerado como "Identidad Proyecto", esta se desarrolla cuando los individuos buscan y construyen una nueva identidad, esta se sustenta en la cultura que poseen, pero, también sobre aquellas otras que puedes examinar. Desde esta posición, la función de la escuela en la sociedad actual ha de compatibilizar dos aspectos fundamentales: primero, compensar las desigualdades de origen, y, segundo, reconstruir los conocimientos, actitudes y pautas de conducta que el alumnado asimila en las interacciones sociales que mantiene su vida extraescolar (Castells; en Sánchez, 2006). Allí los murales decodifican la imagen de la mujer caribe en diferentes matices, que permite elevar su representación dentro del ámbito popular, revalorizándola y elevando su dignidad.

Tabla 5. Representaciones femeninas en los murales Killart 2017

\begin{tabular}{|c|c|c|c|}
\hline No. & $\begin{array}{l}\text { NOMBRE DEL } \\
\text { MURAL }\end{array}$ & DETALLES & IMÁGENES \\
\hline 1 & "AFRO-COLORES" & $\begin{array}{l}\text { Una mujer afrodescendiente con cabello multicolor, que podría } \\
\text { representar esperanza, vida y armonía. En su rostro un antifaz que } \\
\text { ocultaba una mirada llena de palabras y sentimientos escondidos. } \\
\text { En general parecía representar la belleza y alegría de la vida. }\end{array}$ & \\
\hline 2 & "FRAGILIDAD " & $\begin{array}{l}\text { Hay una mujer que parece tener una edad bastante avanzada } \\
\text { que está desapareciendo como si el viento se la llevase. Aunque } \\
\text { hay muy pocas hojas rodeándola, la naturaleza la envuelve como } \\
\text { si ella se pudiera igualar con el viento que la rodea, se ve frágil } \\
\text { y abnegada. Es como si los años le hubieran enseñado todo. } \\
\text { Representa desde la subjetividad la fragilidad de la vida. }\end{array}$ & \\
\hline 3 & "ALEGRÍAS" & $\begin{array}{c}\text { Es una mujer con una taza grande y redonda; ubicada en la parte } \\
\text { superior de su cabeza, representa las mujeres palenqueras, las } \\
\text { cuales salen a vender sus dulces por las calles de la ciudad de } \\
\text { Barranquilla. Está rodeada de casas y de una bandera de la ciudad } \\
\text { al final. Una realidad y un orgullo de las raíces de las cuales ella } \\
\text { proviene. }\end{array}$ & \\
\hline 4 & "AMOR MATERNO" & $\begin{array}{l}\text { Una madre afrodescendiente que amamanta a su hijo, acompañada } \\
\text { de una cayena y el sol. Representa la realidad, el amor fraterno, } \\
\text { lo puro e incorruptible como lo es el amor de una madre: fuerte } \\
\text { y valiente. }\end{array}$ & \\
\hline 5 & $\begin{array}{c}\text { "MADRE } \\
\text { NATURALEZA" }\end{array}$ & $\begin{array}{l}\text { Son cuerpos de mujeres, pero sin cabeza. Hacen alusión a la madre } \\
\text { naturaleza, dado a que de ella emergen o están arriba de ellas las } \\
\text { estaciones y elementos básicos que conforman el mundo natural. } \\
\text { Representan el cuidado e importancia del medio ambiente, su } \\
\text { valor y lo que el estar en estado armónico genera. }\end{array}$ & \\
\hline 6 & $\begin{array}{l}\text { "IDENTIDAD } \\
\text { FEMENINA" }\end{array}$ & $\begin{array}{l}\text { Tres mujeres desde su identidad, aparentan ser del departamento } \\
\text { del Chocó; están rodeadas por hojas y un mensaje que las } \\
\text { acompaña que alude a su valor y orgullo de su ser. Representa en } \\
\text { términos simples el amor y el orgullo de su procedencia. }\end{array}$ & \\
\hline
\end{tabular}

Fuente: Elaboración Natalia Barros, 3 semestre de Psicología. Observaciones directas a imágenes Killart 2017 
Entre tanto las "representaciones masculinas" se contraponen entre las representaciones rural/urbano y lo disímiles que son estos horizontes, dentro del epicentro del país, para los varones. Llama la atención, que todos estos murales, que representan lo masculino, han sido definidos por los artistas franceses, a quienes les parece una realidad muy distinta a la que experimentan en sus países.

Dentro de un mundo rural, está representado por lo cultural y el conflicto del país. Dentro de lo primero: "el hombre caimán" (mural, 1). Aquí es lo referenciado a la cultura anfibia, que dentro de sus propias situaciones emergentes, investigó Fals Borda (1979) y la definió con los contenidos de elementos ideológicos y articula expresiones psicosociales, actitudes, prejuicios, supersticiones y leyendas que tienen que ver con los ríos, caños, barrancos, laderas, playones, ciénagas y selvas pluviales. Además establece sus propias dinámicas de supervivencia (Fals, 1979).

Es tal vez el temor que experimenta el hombre de río, el mismo que está plasmado en la imagen del mural (mural, 1). Dentro de lo segundo, es lo atroz de la guerra, que se ha llevado infinidades de jóvenes y que hoy retorna la esperanza, con los acuerdos de paz (2016); cuántos cerebros fugados allí. Es lo que define Molano (2001), "la diabólica inercia de la violencia". De otro modo, en cuanto a lo urbano, son las situaciones a que se ve aproximado un ciudadano en la gran ciudad. Es la indigencia (mural, 3), que en caso de las ciudades capitales de Colombia, es una de las representaciones más latentes en lugares céntricos. Es la soledad del hombre, cuando el Estado aún no define unas políticas públicas incluyentes, sobre todo en países con el desafío de desarrollo como Colombia. De esa manera, el imaginario que destella una figura más contemporánea (mural, 4), define el deseo de avanzar del hombre, que según la imagen está en el suelo y desea levantarse. Es lo competitivo que se vuelve el mundo desde lo urbano; a diferencia de lo rural, siempre están en una constante búsqueda de ser y estar. Son todas esas complejizaciones de la modernidad en lo urbano (ver tabla 6). En definitiva, la correlación entre las imágenes femeninas y masculinas, muestran o sugieren que; en las primeras hay mayor presencia cultural en la diversidad del cariz de la mujer, desde lo étnico, feminidad, modernidad, laboriosidad. Entre tanto lo masculino, lo representacional, es parte de la realidad que somos como país, aquella desventaja que está a la orden del día en el medio urbano o rural. Aquellas situaciones que permean la vida del varón y que están presentes en la historia social del país, en su inmersión en la guerra, en la marginalidad y todo ello conlleva a la esperanza en la búsqueda de la paz.

Finalmente, el contraste de lo femenino y masculino, es matizado por representaciones de la naturaleza y animales. Es el reflejo del esplendor caribe, de lo exótico de sus paisajes y el verde de su vegetación. Además aquellos animales que hacen parte del escenario caribe, definidos por aves y un reptil. Las aves se simbolizan en los canarios y guacamayas (murales 3 y 4); en otro sentido, son dibujados los pájaros en jaulas domésticas (mural, $5)$; la efigie de otros animales, que no hacen parte de este epicentro, como mamífero (oso) (mural, 2), que además es multiforme y encuentra asidero en la cultura patrimonial, como lo es, el carnaval (Ver tabla 7).

\section{CONCLUSIONES}

\section{Representaciones socioculturales}

En estas imágenes, que hacen parte del proyecto Killart 2017; hay una sincronía entre el presente y el pasado, y en las dimensiones descritas como 
Tabla 6. Representaciones masculinas Killart 2017

\begin{tabular}{|c|c|c|c|}
\hline No. & NOMBRE DEL MURAL & DETALLES & IMÁGENES \\
\hline 1 & $\begin{array}{c}\text { Abstracto: } \\
\text { "HOMBRE CAIMÁN" }\end{array}$ & $\begin{array}{l}\text { La figura representa la fisonomía de un hombre con cabeza de } \\
\text { caimán, el cual se encuentra agachado con una brocha en la } \\
\text { mano creando la ilusión de que es él quien pinta la pared. Su } \\
\text { expresión tímida junto con lo que está acompañándolo representa } \\
\text { "la inhibición de una mente brillante". El Hombre Caimán, dentro } \\
\text { del escenario caribe, representa al hombre que vive a orillas de } \\
\text { rio. Las poblaciones de Plato y Ciénaga en el departamento del } \\
\text { Magdalena, realizan festividades alusivas a su nombre. }\end{array}$ & \\
\hline 2 & $\begin{array}{c}\text { "LO OCULTO BAJO LA } \\
\text { MÁSCARA" }\end{array}$ & $\begin{array}{l}\text { Se ve un fusilero que oculta bajo una máscara la nobleza de su } \\
\text { naturaleza humana, los verdaderos deseos de bondad y amor } \\
\text { que hay en él. Aspira la fragancia de una flor amarilla, que en } \\
\text { términos simples podría representar "la esperanza de un mejor } \\
\text { mañana" que hay dentro de nosotros. Las flores amarillas, son } \\
\text { representadas en la literatura por Gabo, además era una de sus } \\
\text { flores preferidas. }\end{array}$ & \\
\hline 3 & "HABITANTE DE CALLE" & $\begin{array}{c}\text { Un hombre, con la mirada vacía y perdida. Representa una } \\
\text { "realidad social" que se ignora en todo momento, "la indiferencia" } \\
\text { de muchos que es el vivir y sentir de quienes no tienen nada ni } \\
\text { nadie. }\end{array}$ & \\
\hline
\end{tabular}

Fuente: Elaboración Natalia Barrios, 3 semestre de Psicología. Observaciones directas a imágenes Killart 2017

la femenina, masculina y la naturaleza mezclada con los animales. Es en la forma de una construcción que recuerda la historia que se hace legible, solo bajo la imagen de una "constelación", donde el pasado se salvaguarda y se preserva en el presente: "Si se quiere considerar la historia como un texto el pasado ha depositado en ellos imágenes que se podrían comparar a las que son fijadas por una representación (Benjamin, 1974).

En este caso, es parte de una realidad, con las disyuntivas que se presentan sociohistóricamente entre lo femenino y masculino; que aquí es desde la imagen que se hace memoria, el primer caso: entre lo tradicional y moderno; en el segundo, lo rural y urbano. Espacios y significaciones que van definiendo lo que ha sido la mujer y el hombre, en el caso colombiano y caribe, con sus distintas realidades.

En otro sentido, la asociación de la escritura de la historia se hace con el procedimiento de la imagen, su aprehensión es percibir "detrás de cada una de sus frases la transformación de la extrema movilidad en una efigie" (Adorno, 2001). Todo ello conllevaría, a que en el imaginario colectivo pueda entroncarse lo categorial de lo femenino, 
Tabla 7. Representaciones de la naturaleza

\begin{tabular}{|c|c|c|c|}
\hline $\begin{array}{l}\text { NUMERO } \\
\text { DE MURAL }\end{array}$ & $\begin{array}{l}\text { NOMBRE DEL } \\
\text { GRAFITI }\end{array}$ & DETALLES & IMÁGENES \\
\hline 1 & $\begin{array}{l}\text { "ABSTRACCIÓN DEL } \\
\text { COLOR" }\end{array}$ & $\begin{array}{c}\text { La imagen hace alusión a la libre imaginación del hombre; demuestra cómo } \\
\text { "las ideas fluyen y al dejarlas tomar el control pueden formar obras de } \\
\text { arte magnificas", que adquieren una significación propia del espectador. La } \\
\text { subjetividad, la imaginación y lo gestáltico fomentan el entendimiento de } \\
\text { esta representación gráfica. }\end{array}$ & \\
\hline 2 & "EL OSO MUSICAL" & $\begin{array}{c}\text { En el mural, se ve un animal que parece un oso, acompañado por imágenes } \\
\text { abstractas a su lado. Lo sorprendente de este grafiti especialmente es que } \\
\text { sus esquemas de lo básico de la imaginación visto en la anterior van mucho } \\
\text { más allá. La frase para describirlo sería "mente maestra". }\end{array}$ & \\
\hline 3 & "CANARIO" & $\begin{array}{c}\text { Un pájaro montado sobre la rama de un árbol, creando la ilusión de que } \\
\text { está apunto de cantar. Representa "la belleza de la madre naturaleza, pero } \\
\text { también su fragilidad". La naturaleza está en nuestras manos, decidimos } \\
\text { si la destruimos y matamos esa belleza genuina que se esparce delante de } \\
\text { nuestros ojos. }\end{array}$ & \\
\hline 4 & $\begin{array}{l}\text { "HUMANITARIA } \\
\text { NATURALEZA" }\end{array}$ & $\begin{array}{c}\text { Esta efigie la representan animales, que toman sus crías o lo único que se } \\
\text { puede decir es que el termino humanidad merece ser acuñado en un sentido } \\
\text { metafórico a los animales, porque sin duda alguna su "capacidad de amar } \\
\text { y forjar sus crías" rebasa los límites de lo que en el mundo real se puede } \\
\text { tener. }\end{array}$ & \\
\hline 5 & "MUNDO ECUÁNIME" & $\begin{array}{l}\text { Aquí son muchos animales, en su mayoría domésticos y aparentemente } \\
\text { es como si estuvieran en armonía, debido a que todos tienen expresiones } \\
\text { felices y los unos con los otros se encuentran a gusto. Se les brinda el } \\
\text { valor que en realidad tienen, pero ignoramos. Representa la "igualdad", un } \\
\text { "Ilamado al hombre a tratar a los animales como lo merecen" y no como un } \\
\text { "adorno" o algo de lo que tomamos posesión y tratamos a nuestro antojo. }\end{array}$ & \\
\hline
\end{tabular}

Fuente: Elaboración Natalia Barrios, 3 semestre de Psicología. Observaciones directas a imágenes Killart 2017

masculino, además, naturaleza y animales; en ellos sus límites, la preservación de lo determinante y las construcciones que desde lo histórico, pueden potenciarse a lo contemporáneo. Así mismo, la cultura popular local responde a diferentes y múltiples piezas que componen, recomponen $y$ descomponen claves y pensamientos, comunicados mediante visibles e invisibles canales que conducen las aguas y la savia que nutren el accionar cotidiano de los sectores populares (De Andreis, 2016).
A través de este proyecto de aula, se ha logrado la obtención de la "educación como transformación"; propone, superar la acción afirmativa para las minorías y rescatar la visión societal más amplia aportada por el antirracismo. Los efectos liberadores no deben limitarse a las minorías, sino que a la concienciación pedagógica tendrá que dirigirse así mismo hacia la deconstrucción de las excluyentes y opresivas identidades de la mayoría (Diezt y Mateos, 2011). Así el encuentro con los gestores culturales del nivel público y privado, 
permiten sincronizar estas acciones que dentro de lo cultural, permiten un apropiación social para el conocimiento y los acontecimientos sociales, que se entrelazan en las imágenes y que trasmiten nuevos significados en torno a las categorías definidas, como son lo femenino, lo masculino y la naturaleza.

Se vinculan así el valor democrático de la diversidad con el valor de la dilatación de los horizontes culturales, intelectuales, espirituales de todos/as, para enriquecer el mundo particular y colectivo, al adoptar una apertura hacia las diferentes perspectivas de este género, y para que aumenten las posibilidades de desarrollo, exploración e iluminación en el orden de lo intelectual y lo espiritual (Taylor, 1993).

De esa manera, es además de una labor, una responsabilidad de formar y permitir el cometido de la educación, que nos permita tener actos creativos, en esta época en que cada vez más los jóvenes, se comprometen cada vez menos con su proceso formativo; ante eso nos sigue hablando Sabater (1997):

La tarea de educar tiene obvios límites y nunca cumple sino parte de sus mejores -io peores!- propósitos. Pero no creo que ello la convierta en una rutina superflua ni haga irrelevante su orientación ni el debate sobre los mejores métodos con que llevarla a cabo (Sabater, 1997, p. 6).
Considerando lo anterior, ha sido fundamental mi paso por la Universidad Simón Bolívar, en este proceso de enseñanza/aprendizaje; cinco años realizando docencia e investigación, permiten una evaluación constante en la motivación estudiantil, que contribuya a su proceso formativo, que además de dinámico, sea comprensible.

Para finalizar, es posible que el proyecto Killart 2017, esté realizando desde las representaciones definidas (femenino, masculino, naturaleza y animales); educación para el cambio social. Al lograr el producto documental (Aguilar, 2017); se pretende intervenir socialmente, al país, al mundo. En poder definir la realidad a través de la imagen. Siendo el arte un vehiculó, donde lo instantáneo cobre valor, para que a través de la memoria se recuerden los trances que hay como sociedad colombiana, dentro del contexto global; con miras a un profundo desarrollo cultural en la comprensión de lo que se es como mujer u hombre, a su vez, el respeto por la naturaleza y los animales. En correlación con lo anterior, ha sido fundamental, integrar a este trabajo a los/las estudiantes de Psicología, ya que desde sus percepciones y conceptualizaciones, contribuyen a decodificar las imágenes y a asignarles un valor desde la ciencias sociales, más allá de la mera imagen.

\section{REFERENCIAS}

Adorno, T (2001). Sobre Walter Benjamín. Recensiones, artículos, cartas, Madrid, Ediciones Catedra, 2001, pp. 17-45, 46.

Aguilar, A (2017, mayo 31). Dialéctica de la imagen femenina en Killart 2017. [Archivo de Video].Recuperado el 2 de junio de 2017 https:// www.youtube.com/watch? $\mathrm{v}=\mathrm{RJ} 3$ $\underline{\mathrm{GIFH}} 4 \mathrm{YA} \& \mathrm{t}=21 \mathrm{~s}$
Amorós, C., \& De Miguel , A. (2007). Teoría feminista: de la ilustración a la globalización. Del feminismo liberal a la posmodernidad (segunda ed., vol. II). Madrid: Top printer plus.

Araya, S. (2002). "Las representaciones sociales: Ejes teóricos para su discusión". Cuaderno de Ciencias Sociales 127. FLACSO. Costa Rica. 
Benjamin, W (1974), "Paralipomena zu "Uber den Begriff der Geschichte" ", en Rolf Tiedemann y Hermann Schweppenhäuser (eds.), Gesammelte Schriften, vol. 1/3, Frankfurt, Suhrkamp,

De Andreis, A. (2016). Sociología desde el Caribe colombiano. Mirada de un sentipensante. Barranquilla: Ediciones Universidad del Norte.

Dietz, G., \& Mateos, S. (2011). Interculturalidad y educación intercultural en Mexico. Un analisis de los discursos nacionales en su impacto en los modelos educativos mexicanos. Mexico D.F.: Secretaría de Educación Pública.

El Heraldo (10 marzo 2017). Arte contra la pared en la carrera 50. Recuperado el 15 de abril 2017: https://www.elheraldo.co/ entretenimiento/arte-contra-lapared-en-la-carrera-50-335566

El Heraldo (3 de marzo 2017). Barrio Abajo se convertirá en un museo a cielo abierto. Recuperado el 15 de abril 2017: https://www.elheraldo. co/entretenimiento/barrio-abajose-convertira-en-un-museo-cieloabierto-333503

Fals, O (1979). Fundamentos de la cultura anfibia. Recuperado el 16 de abril de 2017: http://www.bdigital. unal.edu.co/1395/3/02CAPI01.pdf
Femenias, M. (2007). El género del multiculturalismo. Buenos Aires: Quilmes edt.

Jodelet, D (1984). En Psicología social, II. Pensamiento y vida social. Psicología social y problemas sociales. Paidós Ibérica SA. Barcelona. $747 \mathrm{p}$

Martinic, S. (2006). Metodología de la investigación social. Santiago: Lom.

Moscovici, S (1984). Psicología social II. Pensamiento y vida social. Psicología social y problemas sociales. Argentina: Paidós. 747 p.

Pardinas, F (1993). Metodología y técnicas de investigación en ciencias sociales. México: siglo 21 editores.

Rojas, M (2015). América imaginaria. Recuperado el 20 de abril 2017: https: //www.youtube.com/ watch? $v=$ YIKu2bdyNPA

Sabater, F (1997). El valor de educar. España: Editorial Ariel.

Sanchez, A. (2006). Interculturalidad, feminismo y educación. Madrid: Los libros de la catarata.

Taylor, C. (1993). El multiculturalismo y politica del reconocimiento. México: Fondo de cultura economica .

Zemelman, H. (1992). Los horizontes de la razón. Barcelona: Anthropos. 